\title{
O GRUPO LEMANN E O NOVO PAPEL DOS APARELHOS PRIVADOS DE HEGEMONIA NO CAMPO DA EDUCAÇÃO NO BRASIL
}

\author{
THE LEMANN GROUP AND THE NEW HEGEMONY \\ PRIVATE APPARATUS TYPE IN BRAZILIAN EDUCATIONAL \\ FIELD \\ EL GRUPO LEMANN Y EL NUEVO TIPO DE APARATO \\ PRIVADO DE HEGEMONÍA EN EL CAMPO EDUCATIVO \\ BRASILEÑO
}

Maria Teresa Cavalcanti de Oliveira'

\begin{abstract}
Resumo: $O$ artigo analisa a atuação do Grupo Lemann que, por intermédio da Fundação Lemann, vem atuando em diversas frentes da política pública de educação no Brasil. O objetivo da análise é explicar os princípios norteadores, os objetivos e as estratégias que orientam suas intervenções no trabalho educativo das escolas de inúmeras redes públicas de ensino. A análise resulta em indicações de um novo papel assumido pelo empresariado brasileiro, a partir dos anos 2000, na disputa de hegemonia no campo educacional. Tais indicações partem do pressuposto da existência de um acelerado processo de neoliberalização, o qual desencadeou novos mecanismos de dominação burguesa focados no campo da educação e que impactam diretamente o papel do Estado no desenvolvimento das políticas públicas para a educação, com vistas em um novo padrão de sociabilidade. Nesse contexto, o projeto neoliberal de educação se institui como instrumento fundamental na construção do consenso em torno das novas estratégias de dominação burguesa. Com base nessas análises, o texto aponta que as mudanças recentes nas políticas públicas para a educação de países dependentes como o Brasil estão longe de ser explicadas como consequência de uma imposição de organismos internacionais da qual governantes locais
\end{abstract}

\footnotetext{
${ }^{1}$ Doutora em Educação pela Pontifícia Universidade Católica do Rio de Janeiro (PUC-RJ). Atua como professora adjunta do Departamento de Gestão de Sistemas Educacionais da Faculdade de Educação da Baixada Fluminense (FEBF) da Universidade do Estado do Rio de Janeiro (UERJ), onde exerce o cargo de Vice-Diretora da FEBF. É pesquisadora vinculada ao grupo de pesquisa do HISTEDBR/FEBF, ao Grupo de Pesquisas Estado, Políticas e Espaço Público (EPEP/EPSJV/FIOCRUZ) e ao Núcleo de Pesquisa sobre Estado e Poder no Brasil (UFF). ORCID iD: http://orcid.org/0000-0000-0000-0000 .E-mail: teresacavalcanti@gmail.com
} 
seriam vítimas. Trata-se, na realidade, de um projeto de reordenamento da dominação burguesa em um contexto de crise orgânica do capital.

Palavras-Chave: Hegemonia - Tendências da Política Educacional - Educação Brasileira.

Abstract: The article analyzes the performance of the Lemann Group which, through the Lemann Foundation, has been acting on several fronts of the public education policy in Brazil. The objective of the analysis is to explain the guiding principles, objectives and strategies that guide their interventions in the educational work of schools in countless public-school network. The analysis results in indications of a new role assumed by the Brazilian business, from the 2000s, in the dispute of hegemony in the educational field. These indications start from the presupposition of the existence of an accelerated process of neoliberalization, which triggered new mechanisms of bourgeois domination focused on the field of education and that directly impact the State's role in the development of public policies for education, with a view to a new sociability pattern. In this context, the neoliberal project of education is instituted as a fundamental instrument in the construction of consensus around the new strategies of bourgeois domination. Based on these analyzes, the text points out that recent changes in public policies for education in dependent countries such as Brazil are far from being explained as a consequence of the imposition of international bodies to which local rulers would be victims. It is, in fact, a project of reordering bourgeois domination in a context of the organic crisis of capital.

Keywords: Hegemony - Educational Policy Trends - Brazilian Education.

Resumen: El artículo analiza el desempeño del Grupo Lemann que, a través de la Fundación Lemann, ha actuado en varios frentes de la política de educación pública en Brasil. El objetivo del análisis es explicar los principios rectores, objetivos y estrategias que guían sus intervenciones en el trabajo educativo de las escuelas en innumerables redes de enseñanza públicas. El análisis arroja indicios de un nuevo papel asumido por los empresarios brasileños, desde la década de 2000, en la disputa de la hegemonía en el campo educativo. Estas indicaciones parten de la presuposición de la existencia de un proceso acelerado de neoliberalización que desencadenó nuevos mecanismos de dominación burguesa centrados en el campo de la educación y que impactan directamente el papel del Estado en el desarrollo de políticas públicas de educación, con miras a un nuevo patrón de sociabilidad. En este contexto, el proyecto neoliberal de educación se instituye como un instrumento fundamental en la construcción del consenso en torno a las nuevas estrategias de dominación burguesa. Con base en estos análisis, el texto señala que los cambios recientes en las políticas públicas para la educación en países dependientes como Brasil están lejos de explicarse como consecuencia de la imposición de organismos internacionales de los que los gobernantes locales serían víctimas. Es, de hecho, un proyecto de reordenamiento de la dominación burguesa en un contexto de crisis orgánica del capital.

Palabras clave: Hegemonía - Tendencias de la Política Educativa - Educación Brasileña.

\section{Introdução}

O que é o Grupo Lemann (GL)? O que explica o fato da Fundação Lemann (FL), uma instituição privada vinculada ao $\mathrm{GL}$, atualmente estar presente em diversas ações no campo da educação pública no Brasil? Que princípios, objetivos e estratégias caracterizam suas intervenções educacionais nas escolas das redes públicas? Tais indagações resultaram no desenvolvimento de uma reflexão centrada no novo papel que o empresariado brasileiro, através de seus aparelhos privados de hegemonia (APH), tem desempenhado mais efetivamente a partir dos anos 2000 na realidade brasileira, no campo da educação em geral. O estudo desenvolvido assume como pressuposto dessas transformações, a existência de um acelerado processo de neoliberalização, 
gerador de novos mecanismos de dominação burguesa que passam a atuar pesadamente no campo das políticas sociais de educação e da saúde; uma dominação de novo tipo que tem impactado de diferentes maneiras o papel das políticas públicas, implementando os princípios da racionalidade científica vinculada ao capital financeiro e sua imperiosa necessidade de viabilizar e implantar o novo padrão de sociabilidade no conjunto da realidade brasileira.

Nesse contexto, vale apontar que o projeto neoliberal de educação - que vem sendo implementado no conjunto do mundo capitalista globalizado, com concepção, gerenciamento e disseminação a cargo dos organismos internacionais com destaque para o papel do Banco Mundial $(\mathrm{BM})^{2}$ - se constitui fundamental instrumento de apoio às_novas estratégias de dominação burguesa, seja via consenso ou coerção. Mas vale destacar que, a despeito da forte influência do BM nas políticas educacionais dos países de capitalismo periférico, o presente estudo sobre o novo papel dos APH, com ênfase no $\mathrm{GL}$, nos permite constatar "o duplo equívoco de pensar a atuação do BM como uma intervenção de fora para dentro (portanto, uma sobre determinação do âmbito internacional sobre o nacional) e como uma imposição unilateral da qual os governantes locais seriam as vítimas" (PEREIRA; PRONKO, 2014, p. 90). É importante esclarecer que, no contexto brasileiro, a intervenção do BM no âmbito da educação vai além de uma mera imposição "externa"; no Brasil, o projeto neoliberal das políticas sociais em curso tem se materializado através de uma articulação de mão dupla, envolvendo não só a agenda elaborada pelo BM como também a ação inovadora e estratégica de atores nacionais, com destaque para o papel de grandes grupos privados e suas articulações junto a governos que resultam numa nova e eficiente acumulação do capital através do acesso direto ao fundo público - envolvendo não só ações com a União, mas também com os Municípios e com os Estados da federação. Ao longo do estudo, tal constatação resultou na concepção da categoria "empresariamento do fundo público", que se mostrou útil e eficiente na compreensão da presença do empresariado no campo da educação pública no Brasil, no contexto de uma acumulação hegemonizada pela financeirização.

Assim, nossa hipótese inicial de estudo se apoia na constatação de que a forte presença do $G L$ na educação no Brasil evidencia um novo tipo de intervenção do empresariado brasileiro nesse campo; para além da adoção da mesma linha de princípios existentes no projeto internacional de educação divulgado pelo BM, vale destacar que as atuais interferências dos grupos empresariais são também movidas a interesses financeiros específicos e estratégicos tendo em vista a atual fase do capital, um "regime de acumulação com dominância financeira" (CHESNAIS, 2003; p. 46). Não por acaso, grupos empresariais têm fomentado e desenvolvido um movimento de aproximação com o Estado em seus diferentes níveis, concentrando forças tanto em intervenções diretas nas políticas públicas de educação ${ }^{3}$ (governo federal, MEC), quanto

\footnotetext{
2 Acerca desse processo, é valido consultar Pronko (2019).

${ }^{3}$ O Plano de Desenvolvimento da Educação (PDE) foi lançado em 24 de abril de 2007 - Decreto Lei 6.094/2007 -, durante o segundo governo Lula (BRASIL, 2007), em conjunto com o Plano de Metas Compromisso Todos pela Educação. O PDE foi concebido pelo Movimento Todos Pela Educação (TPE), criado em 2006, que congrega representantes de diferentes setores da sociedade, tais como: gestores públicos, educadores, pais, alunos, pesquisadores, profissionais de imprensa e fundamentalmente empresários diretamente interessados nos atuais encaminhamentos da educação no Brasil.
} 
em ações focais e locais, ligadas às secretarias municipais de educação ${ }^{4}$ e secretarias de estado.

Outro fundamental e concomitante aspecto que confirma e direciona a necessidade de se estudar e compreender tais mecanismos é a elevadíssima ausência de transparência quanto aos procedimentos que envolvem: a relação da sociedade política com tais grupos empresariais, o foco de seus interesses e a sistematização de suas estratégias de atuação. Estamos diante de ações articuladas, não explicitadas, que se caracterizam por evidenciar, em distintos graus, a vinculação ao ideário neoliberal expressa na defesa e legitimação da privatização, no processo de focalização das políticas públicas e na descentralização de encargos sociais via parcerias públicoprivadas. Um conjunto de medidas que naturalizam e atualizam os novos princípios da organização da vida social; uma nova sociabilidade que legitima o individualismo como valor moral radical articulado que se articula à uma intensa, mas pouco orgânica "participação", consubstanciada numa democracia consentida ${ }^{5}$ (OLIVEIRA, BARROS, 2015), na medida em que trabalha, superficial e despolitizadamente, as contribuições da sociedade civil, através de seus múltiplos atores. Assim, concomitantemente às estratégias vinculadas ao empresariamento do fundo público, constata-se um processo de "publicização da lógica empresarial" fundamental e necessária à nova sociabilidade de cunho neoliberal: um processo que dissemina o ideário empresarial na ambiência e funcionamento individual das escolas públicas e impacta singularmente as políticas públicas de educação e o conjunto do sistema público escolar brasileiro.

Numa tentativa inicial de sistematização desse conjunto diversificado de determinações presentes no estudo pretendido sobre a presença da FL na educação pública no Brasil, essas duas categorias - "empresariamento do espaço público" $e$ "publicização da lógica empresarial" - nos auxiliam a sistematizar a natureza das principais estratégias que vem sendo adotadas por grupos privados no âmbito da educação, tanto na formação política quanto na formação escolar. Uma ajuda que nos permite compreender o funcionamento do projeto "internacionalizado" de educação em curso no país, tendo em vista a dificuldade de acesso a fontes básicas para a construção de um conhecimento sistemático envolvendo a diversificada atuação do BM em diferentes contextos; o mesmo acontece com as dificuldades em relação ao mapeamento e compreensão do novo papel desempenhado pelo Estado, envolvendo tanto a sociedade política ou máquina institucional, quanto a sociedade civil, espaço de referência dos grandes grupos privados e suas ações.

Dessa forma, pautado pelos internacionalmente conhecidos processos de privatização, focalização, descentralização dos encargos e ênfase na lógica da

\footnotetext{
${ }^{4}$ Dentre as ações locais, destacam-se as estratégias direcionadas às escolas das redes municipais em distintos Estados da federação, envolvendo: estratégias de formação dos diretores das redes públicas de ensino, políticas editoriais centradas na produção de livros didáticos, concepção de novas metodologias e formas de ensino, etc.

${ }^{5}$ Partindo do pressuposto de que nas sociedades capitalistas, a democracia se explicita a partir do conjunto dos interesses de classes (FERNANDES, 1986; p. 50), "democracia consentida" é um conceito trabalhado por Oliveira e Barros (2015; p 160) voltado à compreensão do contexto dos anos de 1995 a 2006 no Brasil (governos FHC e 1. governo Lula da Silva) que expressa "uma relação social que se constrói por meio de princípios, práticas, estratégias e precisa da colaboração das classes trabalhadoras nessa construção. Esse processo de estímulo ao colaboracionismo pressupõe a execução de ações de responsabilidade social, na tentativa de reduzir as tensões e disputas entre classes e frações de classes (MARTINS, 2009). $\mathrm{Na}$ acepção gramsciana, essa participação visa a "excluir a grande política no âmbito interno da vida estatal e reduzir tudo à pequena política” (GRAMSCI, 2003; p.21).”
} 
participação (NEVES, 2002) que caracterizam o novo ideário do capital neoliberal, o estudo sobre o GL e a FL nos possibilitará compreender um fato novo: o papel que os grandes grupos privados têm desempenhado no âmbito da educação pública no Brasil de hoje. Um papel significativamente novo por parte do empresariado na medida em que, a despeito de todas as dificuldades existentes, a educação pública desde sua institucionalização tem sido historicamente trabalhada pelo Estado brasileiro, via sociedade política.

Para dar conta do encaminhamento do estudo em curso, o presente texto se estrutura em três partes. Uma introdução onde são apontados os pressupostos assumidos assim como as hipóteses que têm sido exploradas tendo em vista o uso das categorias apresentadas. Na continuidade serão desenvolvidas análises apoiadas nas categorias já apresentadas na introdução, só que apoiadas em distintas empirias: inicialmente será analisado o papel do $\mathrm{GL}$, um dos maiores grupos privados do país, que marca a gênese de um complexo projeto educacional; posteriormente, serão elencadas algumas compreensões iniciais sobre a atuação da $\mathrm{FL}$, uma das instituições do grupo, que se singulariza tanto pelo seu inovador papel no que se refere ao acesso ao fundo público quanto pelo desenvolvimento de atividades voltadas para a "gestão dos sistemas públicos de ensino no Brasil" ${ }^{\prime \prime}$. Ao final desta parte são apresentadas algumas considerações gerais sobre o momento atual do estudo e suas possibilidades de desdobramentos.

\section{O Grupo Lemann: a gênese de um projeto de educação}

Gerada no bojo de diversas iniciativas concebidas e implementadas no âmbito da área educacional a partir dos anos de 1990 no Brasil, a FL se vincula ao GL, liderado pelo empresário suíço-brasileiro Jorge Paulo Lemann. Dono de um vasto portfólio de investimentos nacionais e internacionais, este empresário e seu grupo de investidores detém atualmente o controle de amplos conglomerados empresariais: a AnheuserBusch InBev (AB InBev), considerada a maior cervejaria do mundo; a Kraft Heinz, quinta maior empresa de alimentos e bebidas do planeta; a Brands International, terceira maior operadora de fast-food do mundo; além das Lojas Americanas, quarta maior varejista do Brasil. Em matéria da Revista Veja, intitulada "Lemann e o sonho de transformar a educação brasileira", Jorge Paulo Lemann, referindo-se especificamente aos seus empreendimentos educacionais, deixa claro que tem uma nova obsessão e expressa um desejo que preocupa educadores e pensadores críticos da lógica do capital: "criar um projeto educacional de impacto sem precedentes no Brasil" (CERQUEIRA, 2017).

Diante de tão poderosa estrutura econômica, a compreensão do papel e do interesse da FL pela educação no Brasil tem suas origens nas ações desenvolvidas inicialmente no GL, palco das primeiras investidas voltadas para intervenções formativas e, portanto, gênese de um ambicioso projeto de educação empresarial vinculado ao ideário das novas estratégias de administração científica e de gestão do mundo do trabalho, mas - o que se destaca como mais impactante e inovador - estrategicamente

${ }^{6}$ Site da Fundação Lemann, www.fundacaolemann.org.br, consultado em 13/03/2011. 
relacionado às novas possibilidades de acumulação disponibilizadas pelo atual estágio de desenvolvimento do capital financeirizado. Sua primeira investida institucionalizada na educação se deu em 1991, com a criação da Fundação Estudar, vinculada ao Banco Garantia, de Jorge Paulo Lemann e outros sócios. Em seu sítio na web, a Fundação Estudar é descrita como: "uma organização sem fins lucrativos que acredita que o Brasil será um país melhor se tivermos mais jovens determinados a seguir uma trajetória de impacto. Por isso, disseminamos uma cultura de excelência e alavancamos os estudos e a carreira de universitários e recém-formados" (FUNDAÇÃO ESTUDAR, 2011, s./p. - texto em htm). Sua missão é "criar oportunidades para gente boa sonhar grande e transformar o Brasil" e sua atuação se desenvolve a partir de 3 projetos: 1) "Líderes Estudar" - desenvolvimento profissional, integração em rede e apoio financeiro para cursar as melhores universidades do mundo; 2) "Estudar Fora" - histórias inspiradoras, oportunidades de bolsa e orientação para quem sonha viver uma experiência acadêmica no exterior; 3) "Estudar Na Prática" - entrevistas com líderes, o dia a dia de trabalho em diferentes setores e cursos que estimulam melhores decisões de carreira.

Numa sucinta análise, a Fundação Estudar se volta a uma "con-formação" de "jovens determinados a seguir uma trajetória de impacto", uma estratégica formação, concebida e gerada, não numa instituição escolar, mas num banco de investimentos. Tal Fundação evidencia a hegemonia do capital financeirizado, claramente preocupado e/ou interessado em estratégias formativas e educativas diferenciadas. Ao assumir o objetivo de "despertar o potencial de jovens brasileiros através da formação de uma comunidade de líderes, o estímulo à experiência acadêmica no exterior e o apoio à tomada de decisão de carreira" (WIKIPÉDIA, 2018, s./p. - texto em htm), a Fundação exalta uma vivência no exterior articulada às histórias de vida de líderes que validam determinado caminho profissional. Ou seja, em suas primeiras investidas, as estratégias implementadas pelo $G L$ na área da educação se deram no âmbito de uma gestão empresarial vinculada à lógica do capital financeiro claramente marcada pelo investimento na formação de lideranças - uma formação nova e específica para um novo sujeito neoliberal, submetido a forte lógica meritocrática articulada a uma proatividade em atualizar-se e aperfeiçoar-se continuamente e, sobretudo, de envolver-se organicamente com os objetivos da empresa. O homem neoliberal é o homem competitivo, inteiramente imerso na competição mundial (DARDOT; LAVAL, 2016). Trata-se de um novo homem necessário à nova sociabilidade do capital financeirizado.

\begin{abstract}
Em outros termos, o dever de se qualificar dentro das expectativas do mercado, e, mais ainda, o de compreender essas expectativas e elaborar um plano, nas condições e recursos próprios, para atendê-las e garantir a própria "empregabilidade", tornou-se, sob a teoria do capital humano, um "empreendimento" a ser assumido individualmente pelos/as trabalhadores/as. Um dispêndio a mais na agenda do/a portador/a da força de trabalho, mas que não deve ser visto como "custo" e, sim, como "investimento" [...] (ANTUNES; PINTO, 2017, p. 102).
\end{abstract}

Nos anos que se seguem, as iniciativas educacionais do GL se ampliam e se complexificam, resultando num eficiente mecanismo de capacitação de jovens - uma capacitação voltada ao mundo empresarial, financeiro e do livre mercado, apoiada numa formação para o trabalho que ressignifica o que denomina "competências" e "qualidades" presentes em comportamentos e subjetividades relacionadas com os princípios de liderança, competitividade, empreendedorismo, privatização, 
desregulamentação, flexibilização etc. Os requisitos da nova formação voltada aos jovens trabalhadores devem se pautar nos aportes de uma educação genericamente ampla, flexível e pragmática, voltada à resolução de problemas e ao desenvolvimento da capacidade para aprender novos processos.

[...] [o novo sujeito] deve cuidar constantemente para ser o mais eficaz possível, mostrar-se inteiramente envolvido no trabalho, aperfeiçoar-se por uma aprendizagem contínua, aceitar a grande flexibilidade exigida pelas mudanças incessantes impostas pelo mercado. Especialista de si mesmo, empregador de si mesmo, inventor de si mesmo, empreendedor de si mesmo: a racionalidade neoliberal impele o EU a agir sobre si mesmo para fortalecer-se e, assim, sobreviver na competição. [...] a economia torna-se uma disciplina pessoal. Foi Margareth Thatcher que deu a formulação mais clara dessa racionalidade: "A economia é $O$ método. O objetivo é mudar a alma" (DARDOT; LAVAL, 2016; p. 328, 331 - grifos nossos).

Outro aspecto de destaque nas estratégias formativas do GL refere-se ao vínculo com um projeto globalizado que pauta o ideário e a agenda da nova administração científica voltada à uma sociabilidade obrigatoriamente flexível, descentralizada, centrada numa participação formal (e superficial) dos indivíduos. Tais aspectos estão presentes no projeto internacional de formação do sujeito neoliberal, concebido e legitimado através da produção de intelectuais orgânicos da burguesia dos países centrais; intelectuais de novo tipo, em sua maioria, vinculados a instituições que funcionam como think tanks $s^{7}$ da nova lógica da formação/educação neoliberal, ou seja, uma lógica em defesa da plena submissão da formação escolar e política às necessidades do mercado de trabalho, legitimadora do universo empresarial financeiro, do ideário privatista e promotora da pedagogia das competências articulada a uma educação flexibilizada, que se dá ao longo de toda a vida, de maneira fragmentada, através de múltiplas e diversificadas ofertas de pacotes educacionais disponibilizados num amplo mercado. Tendo em vista uma necessária disseminação na vida social, tais princípios são afirmados em impactantes megaeventos organizados em torno de intelectuais estrangeiros que vêm ao Brasil propagar suas incríveis e exitosas experiências educacionais e formativas. Fica evidente o uso do campo da educação como eficiente instrumento de mediação e disseminação das premissas do ideário neoliberal voltado para a construção da nova sociabilidade e do novo sujeito empresarial/neoliberal. Ou seja, o GL não só media e incrementa como dissemina o novo ideário, atuando hegemonicamente através de uma pedagogia política, sutilmente presente no dia a dia dos seus "colaboradores", trabalhando no âmbito de uma educação política e de uma educação escolar vivenciada em estabelecimentos de reconhecida excelência no desenvolvimento desses novos requisitos educacionais.

Numa tentativa de síntese parcial, vale afirmar que a atuação do GL no campo da educação no Brasil se caracteriza por duas estratégias de referência principais. Tanto pela valorização e disseminação dos princípios do mundo empresarial na sociedade, disseminada e implementada através da educação, o que resulta numa eficiente "publicização da cultura empresarial", quanto pelo que entendemos ser o mais

\footnotetext{
${ }^{7}$ David Harvey assinala que o surgimento dos "think tanks" se dá nos anos de 1970, momento no qual o capital precisava de um projeto coletivo que organizasse uma frente ideológica em defesa das ideias neoliberais de Freidrich Hayek e Milton Friedman. Naquele contexto era impossível que tais iniciativas se organizassem nas universidades porque o movimento estudantil era forte demais e os docentes progressistas (RISAGER, 2016).
} 
determinante aspecto dessa recente atuação de grupos privados - "o empresariamento do fundo público", uma novidade que convive harmonicamente com as tradicionais estratégias de acumulação da riqueza. Numa tentativa de sistematização inicial, a presença dessas duas estratégias de referência se expressa em graus distintos no conjunto das iniciativas educacionais desenvolvidas pelo $\mathrm{GL}$, que se diferenciam em função dos públicos atingidos e seus específicos contextos: a) ações educativas com fins lucrativos, voltadas para a formação das elites; b) ações voltadas para a formação dos intelectuais orgânicos da nova sociabilidade neoliberal (através de eventos centrados em estudos, debates, reflexões e mecanismos de planejamento e sistematização das estratégias mais adequadas de intervenção na realidade educacional); e c) ações "ditas" filantrópicas, sem fins lucrativos aparentes.

No âmbito das ações com fins lucrativos e iniciativas de cunho educacional privado, o GL tem desenvolvido um mercado de educação gerenciado através de um fundo de investimentos denominado "GERA Venture Capital", descrito como uma "empresa focada em educação" que investe "em empreendedores de alto potencial com o duplo objetivo de gerar impacto relevante na educação e obter retornos financeiros atrativos". O mais recente investimento do "GERA Venture Capital" é uma startup ${ }^{8}$ que recentemente deu origem a holding Eleva Educação, inaugurada em janeiro de 2017, com o objetivo de construir uma rede de escolas de alta qualidade acadêmica (Cf:: CERQUEIRA, 2017). No momento, tal fundo articula quatro grandes redes de colégios dedicados ao ensino elementar, cursos pré-vestibular e cursos de idiomas que, juntos, compõem hoje o segundo maior grupo de escolas privadas do país.

Em se tratando das ações do GL voltadas para a formação dos intelectuais orgânicos da nova sociabilidade neoliberal, o destaque fica por conta do "Projeto Transformar", "pensado de forma a apresentar questões e sugestões que emergem de um universo [educacional] em ebulição". Suas ações se concentram em publicações de impacto visual e num evento anual de grandes proporções que conjuga palestras proferidas por intelectuais de referência no campo das novas reconfigurações neoliberais da educação no mundo e no Brasil. É um evento totalmente gratuito e seu público-alvo são pessoas convidadas, oriundas do setor privado e do setor público da educação, conjugando professores e profissionais da educação em geral envolvidos principalmente com a gestão da educação (pública ou privada), em seus múltiplos aspectos. No ano de 2014, foram trabalhados no evento "9 grandes temas transversais identificados como tendências na educação, suas definições e exemplos de aplicação", sendo cada temática complementada com questões, fontes, links e sugestões para uma pesquisa aprofundada. O conjunto do material impacta pelo apuro visual e tecnológico, além do nível de detalhamento presente na sua concepção - seja nas publicações em papel ou nos sites disseminados nas mídias. Dentre os temas trabalhados em 2014 e 2015, destacam-se os seguintes títulos de palestras: "Personalização: um caminho para cada aluno"; "Ensino híbrido: o poder de misturar o on-line e o off-line"; "Competências para o século XXI"; "O (novo) professor e sua formação"; "Como algumas redes públicas conseguiram flexibilizar seus modelos"; "Empreendedorismo em Educação"; dentre outros (Cf.: TRANSFORMAR A EDUCAÇÃO, 2018).

\footnotetext{
${ }^{8}$ Segundo a revista EXAME, "uma startupé um grupo de pessoas à procura de um modelo de negócios repetível e escalável, trabalhando em condições de extrema incerteza" (MOREIRA, 2016, s./p. - texto em html).
} 
No âmbito das iniciativas educacionais filantrópicas e sem fins lucrativos "aparentes", o grande destaque fica por conta da $\mathrm{FL}$, um estudo que, por ainda se encontrar numa fase introdutória, será apresentado através de questões ainda em processo de aprofundamento.

\section{A Fundação Lemann e o empresariamento do fundo público}

Até o momento, o grande destaque do estudo tem ficado por conta do papel desempenhado pela $\mathrm{FL}$ junto às redes de educação pública, com ênfase nos espaços das escolas públicas de Educação Básica no Brasil. Representando a grande novidade presente no recente papel dos grupos privados na educação, as parcerias públicoprivadas desenvolvidas entre as secretarias municipais de educação e grupos privados, tais como a $\mathrm{FL}$, desenvolvem uma nova estratégia de acumulação da riqueza que passa a se dar através do acesso direto ao fundo público.

Ou seja, compreender o que está em jogo nessa nova estratégia burguesa de acumulação da riqueza pressupõe o entendimento articulado de distintas esferas de determinações: a) o entendimento das características superestruturais resultantes da lógica de funcionamento da sociedade vinculada ao capitalismo financeiro; b) a identificação das características do capitalismo periférico no contexto da realidade brasileira - o novo Estado burguês e suas novas formas e atuação; e c) o novo papel dos APH expressos em estratégias de atuação presentes em instituições como a FL.

A seguir são apresentados os aspectos que irão direcionar cada uma das esferas explicativas da nova acumulação burguesa no Brasil a serem posteriormente aprofundados na pesquisa.

O primeiro conjunto de determinações a ser resumidamente apresentado referese ao entendimento das estratégias de acumulação, legitimadas e implementadas pela atual etapa do capitalismo financeirizado. Em relação estreita com a mundialização do capital, trata-se de uma etapa particular do estágio imperialista compreendido como a dominação interna e internacional do capital financeiro. Segundo Chesnais,

\footnotetext{
O crescimento espetacular das transações financeiras foi um dos fatos mais significativos da década de 80 e já marcou os primeiros anos da década de 90 . Efetivamente, a esfera financeira representa a ponta-de-lança do movimento de mundialização da economia; é nessa esfera que as operações do capital envolvem os montantes mais elevados; é aí que sua mobilidade é maior; é aí que, aparentemente, os interesses privados recuperaram mais completamente a iniciativa, em relação ao Estado (CHESNAIS, 1998; p. 11).
}

Articulado às estratégias do novo regime de acumulação com dominância financeira se situa o segundo conjunto de determinações que conjuga as características e a subalternidade de um capitalismo periférico como o brasileiro, o que articula aspectos tais como: o comportamento dos grupos privados e suas novas estratégias de acumulação de riqueza; o novo papel do Estado no Brasil - um Estado mínimo para os trabalhadores e máximo para os grandes grupos privados; as novas estratégias de gestão da dívida pública, e, nesse contexto presença das novas possibilidades de captura e punção do fundo público. 
No contexto da financeirização do capitalismo, da hegemonia do capital portador de juros com apoio dos Estados nacionais, e de crise estrutural desse modo de produção e reprodução social, a dívida pública se torna um mecanismo fundamental de punção da riqueza socialmente produzida, engendrando também a expropriação de direitos, por meio da captura, da punção do fundo público. Trata-se de uma dinâmica que envolve todos os trabalhadores ao sul e ao norte da Linha do Equador, mediada evidentemente pelas especificidades e pela correlação de forças entre as classes e seus segmentos em cada espaço nacional (BEHRING, 2017; p. 11; grifos meus)

Já a compreensão do novo papel do Estado brasileiro no remete aos anos de 1995, primeiro governo de Fernando Henrique Cardoso que deu início ao processo de reorganização do Estado brasileiro através da implantação da reforma do aparelho de Estado, coordenada pelo Ministério da Administração e Reforma do Estado (MARE), que legitimou as chamadas "entidades públicas não estatais", também denominadas "entidades do terceiro setor", "entidades sem fins lucrativos", "organizações não governamentais", "organizações voluntárias" e "organizações públicas não estatais", também conhecidas como ONGs.

No âmbito do terceiro conjunto de determinações se colocam as características centrais do que denominamos de empresariamento do fundo público, um novo e estratégico mecanismo de acumulação da riqueza da burguesia via acesso ao fundo público. Através das parcerias público-privadas, grupos privados como a FL se articulam às secretarias municipais e estaduais de educação. Uma situação multifacetada que para além do uso do fundo público e suas implicações, acaba materializando os princípios de referência neoliberal da educação pública, impactando e influenciando distintas dimensões do processo da escolarização pública: suas escolas, os professores das redes de ensino, e fundamentalmente crianças, jovens e adultos das classes menos favorecidas.

Ainda que de maneira incompleta, o atual estágio do estudo pretendido aponta questões que nos permitem concluir que o projeto de educação empresarial praticado por grupos privados tais como o $\mathrm{GL}$ e a $\mathrm{FL}$, materializam o novo papel que vem sendo assumido pelo empresariado brasileiro em relação à educação em geral e à educação pública no Brasil, em particular. Tais projetos se constituem numa exitosa iniciativa organicamente concebida pela ofensiva empresarial hegemonizada pelo capital financeiro em âmbito mundial, direcionada à construção coercitiva do consenso sobre a nova sociabilidade do capital.

\section{Conclusão}

Ainda que de maneira incompleta, o atual estágio do estudo pretendido aponta elementos que nos permitem concluir que o projeto de educação empresarial praticado por grupos privados, tais como o GL e a FL, efetivamente materializam o novo papel que vem sendo assumido pelo empresariado brasileiro em relação à educação em geral e à educação pública no Brasil, em particular. Cabe afirmar que, diante da complexidade das estratégias adotadas, da falta de transparência e do volume de informações envolvidas nessas novas formas de ação empresarial, constata-se a necessidade de se trabalhar para compor um amplo mapeamento e respectiva compreensão dos mecanismos e estratégias utilizadas. 
O que se destaca nas análises elaboradas é o fato de que tais transformações envolvendo tanto o novo papel do Estado quanto e a nova atuação dos grupos empresariais, também tem ocorrido em outros países tendo em vista o fortalecimento de um liberalismo clássico radical, numa conjuntura onde os direitos políticos e sociais tem sido significativamente relegados a um segundo plano. $O$ novo modelo de sociabilidade em questão, precisa de uma sociedade centrada no individualismo como valor moral radical; um indivíduo inserido no livre-mercado, que faz escolhas num ambiente concorrencial e que não conta com o Estado para viabilizar sua existência. Nesse contexto as desigualdades sociais se justificam sendo percebidas, não como um tendencioso desequilíbrio econômico, mas como uma nova hierarquia social que se explica pela desigualdade de mérito. $O$ ingrediente fundamental para o estabelecimento dessas transformações que se fazem necessárias à nova sociabilidade, é a educação e a escola. Segundo Freitas (2019), através da educação e da escola, têm se dado processos de distintas naturezas (gerenciamento empresarial da escola, processos avaliativos externos e internos, bases comuns e currículos superficializados etc.) que têm como foco familiarizar tanto os profissionais da educação quanto os estudantes com a lógica da concorrência e com a vivência da meritocracia.

Tais projetos se constituem em uma exitosa iniciativa organicamente concebida pela ofensiva empresarial hegemonizada pelo capital financeiro em âmbito mundial, direcionada à construção coercitiva do consenso sobre a nova sociabilidade do capital. Ou seja, o estudo desenvolvido sobre o GL e a FL é parte de um projeto global que se desenvolve com ampla capilaridade, envolvendo distintas dimensões. Assim concluímos nosso esforço em apontar as amplas determinações que nos permitem compreender criticamente as estratégias que vêm sendo desenvolvidas no âmbito da educação, da formação política e da formação escolar pública no Brasil de hoje.

\section{Referências}

ANTUNES, Ricardo; PINTO, Geraldo Augusto. A Fábrica da educação: da especialização taylorista à flexibilização toyotista. São Paulo, Ed. Cortez, 2017. 117 p.

BEHRING, Elaine Rossetti. A Dívida e o calvário do Fundo Público IN: Revista ADVIR - Associação dos Docentes da Universidade do Estado do Rio de Janeiro. No. 36 (julho de 2017). Rio de Janeiro, 2017.

BRASIL. Decreto $\mathbf{n}^{\circ}$ 6.094, de 24 de abril de 2007. Dispõe sobre a implementação do Plano de Metas Compromisso Todos pela Educação, pela União Federal, em regime de colaboração com Municípios, Distrito Federal e Estados, e a participação das famílias e da comunidade, mediante programas e ações de assistência técnica e financeira, visando a mobilização social pela melhoria da qualidade da educação básica. Brasília (DF): 2007. Disponível em: $<$ http://www.planalto.gov.br/ccivil 03/ ato2007-2010/2007/decreto/d6094.htm>, acesso em 01/04/2018.

CERQUEIRA, Sofia. Lemann e o sonho de transformar a educação brasileira. Rio de Janeiro: Abril, 2017. Veja Rio. Disponível em: <http://vejario.abril.com.br/cidades/lemann-e-o-sonho-detransformar-a-educacao-brasileira/ $>$, acesso em 04/02/2017.

CHESNAIS, François. Introdução Geral IN: CHESNAIS, François (org.). A mundialização financeira: gênese, custos e riscos. São Paulo: Xamã, 1998.

CHESNAIS, François et al. Uma nova fase do capitalismo ? São Paulo: Xamã, 2003. (Seminário marxista: questões contemporâneas). 
DARDOT, Pierre; LAVAL, Christian. A nova razão do mundo: ensaio sobre a sociedade neoliberal. São Paulo: Boitempo, 2016.

FERNANDES, Florestan. Nova República? Rio de Janeiro: Jorge Zahar, 1986.

FONTES, Virginia. Sociedade civil empresarial e a educação pública - qual democracia?, 2018 (mimeo.).

FREITAS, Luiz Carlos. Entrevistando Luiz Carlos de Freitas. Boletim GEPEC/FACED/UFBA, Salvador, Bahia, Brasil, dezembro de 2019 - ano 4, n.7.

FUNDAÇÃO ESTUDAR. Fundação Estudar - Documentários 20 anos. S./l.: 2011. Diaponível em: <http://www.youtube.com/watch?v=XoDMzfHC9RY>, acesso em 31/03/2018.

GRAMSCI, Antonio. O leitor de Gramsci: escritos escolhidos. Organização de Carlos Nelson Coutinho. Rio de Janeiro: Civilização Brasileira, 2011.

Cadernos do Cárcere, v. 03. Maquiavel. Notas sobre o Estado e a política. São Paulo: Civilização Brasileira, 2003.

LEHER, Roberto; MOTTA, Vânia Cardoso. Políticas educacionais neoliberais e educação do campo IN: CALDART, Roseli; PEREIRA, Isabel; ALENTEJANO, Paulo; FRIGOTTO, Gaudêncio (Orgs.). Dicionário da Educação do Campo. Rio de Janeiro, São Paulo: Escola Politécnica de Saúde Joaquim Venâncio, Expressão Popular, 2012.

MOREIRA, Daniela. O que é uma startup? Revista Exame PME, Rio de Janeiro, 03/02/2016. Disponível em: https://exame.abril.com.br/pme/o-que-e-uma-startup/, acesso em 01/04/2018.

NEVES, Lucia M. W. (Org.). A nova pedagogia da hegemonia: estratégias do capital para educar o consenso. São Paulo: Xamã, 2005.

As massas trabalhadoras começam a participar do banquete, mas o cardápio é escolhido à sua revelia, ou democracia e educação escolar nos anos iniciais do século XXI. In: Osmar FÁVERO; Giovanni SEMERARO. (Orgs.). Democracia e construção do público no pensamento educacional brasileiro. $2^{a}$ ed. Petrópolis (RJ): Vozes, 2002, v. 1, p. 163-174.

OLIVEIRA, Maria Teresa Cavalcanti; BARROS, Vanja da Rocha Monteiro. Mudanças nas estratégias políticas de implantação da reforma da escolarização básica IN: NEVES, Lucia M. W.; MARTINS, André (Orgs.). Educação Básica: tragédia anunciada ?. São Paulo: Xamã, 2015.

PEREIRA, João Marcio; PRONKO, Marcela. A Demolição de Direitos. Um exame das políticas do Banco Mundial para a educação e a saúde (1980-2013). Rio de Janeiro: Escola Politécnica de Saúde Joaquim Venâncio, 2014.

PRONKO, Marcela A. Modelar o comportamento: novas estratégias do banco mundial para a educação na periferia do capitalismo. RTPS - Rev. Trabalho, Política e Sociedade, Vol. IV, $n^{\circ} 06$, p. 167-180, Jan.-Jun./2019 - ISSN 2526-2319

RISAGER, Bjarke Skærlund. Neoliberalismo é um projeto político: entrevista com David Harvey. Tradução de Sean Purdy. S./l.: 27 de julho de 2016. Disponível em: < http://blogjunho.com.br/neoliberalismo-e-um-projeto-politico-entrevista-com-david-harvey/>, acesso em 01/04/2017.

TRANSFORMAR A EDUCAÇÃO. Sobre. S./l.: Fundação Lemann; Porvir; Inspirare; Instituto Península, 2018. Disponível em < http://transformareducacao.org.br/>, acesso em 01/04/2018.

WIKIPÉDIA. Jorge Paulo Lemann. S./l.: Wikimedia, 2018. Dispónível em: < https://pt.wikipedia.org/wiki/Jorge_Paulo_Lemann>, acesso em 23/03/2017.

Submetido em: $\quad 30-11-2019$
Aceito em:

